\title{
RESEARCH NOTE \\ Does the association between teen births or abortions and educational attainment vary by socioeconomic background in Finland?
}

\author{
Heini Väisänen University of Southampton, UK \\ h.e.vaisanen@soton.ac.uk
}

(Received April 2017 Revised December 2017)

http://dx.doi.org/10.14301/llcs.v9i2.463

\section{Abstract}

Teen mothers often have a lower socioeconomic position as adults than other women due to selection, opportunity costs of childbearing, or both. Few studies examine whether that is the case after an induced abortion as well. Also, few studies explore whether the strength of the association between teen pregnancy and adulthood socioeconomic position differs by family background. This study uses Finnish register data of 53,252 women born between 1975 and 1979 to examine with logistic regression whether the likelihood of having tertiary education depends differently on teen birth and abortion experiences by parental socioeconomic position. I also control for and report whether having a partner providing childcare helps mitigate the negative association between teen motherhood and education. The results show teen mothers had lower odds than those who aborted to have tertiary education, and both groups were behind those with no teen pregnancy. These groups' education did not vary statistically significantly by family background, although the gap in the probability of having tertiary education between teen mothers and those with no teen pregnancy among the lowest socioeconomic backgrounds was $43 \%$-points, and only $27 \%$-points among the highest. Teen mothers with and without a partner had similar probabilities of having tertiary education (8$11 \%)$. Those who had an abortion and subsequently separated from their partner, however, had similar probability of having tertiary education as teen mothers (13\%), although others who had an abortion had a much higher probability (20\%). Selection shapes these relationships. Survey and register data should be combined to study these associations using methods of causal inference.

\section{Keywords}

Teenage pregnancy; induced abortion; Finland; register data; socioeconomic position 


\section{Introduction}

There is an association between starting childbearing in adolescence and low socioeconomic position later in life (Assini-Meytin \& Green, 2015; Hoffman, 1998; Kane, Morgan, Harris, \& Guilkey, 2013; Lawlor \& Shaw, 2002; Mollborn, 2010; Olausson, Haglund, Weitoft, \& Cnattingius, 2001; Paranjothy, Broughton, Adappa, \& Fone, 2009; Taylor, 2009). This may be due to opportunity costs of having children, which make it challenging to study and build a career (Becker, 1991); or due to selection into early parenthood of those from low socioeconomic backgrounds and with low career aspirations (Geronimus \& Korenman, 1992; Smith \& Roberts, 2011). Many studies have aimed to establish whether teenage motherhood is causally linked with lower socioeconomic position in adulthood using methods such as propensity score matching (Lee, 2010), inverse probability weighting (Diaz \& Fiel, 2016), sibling fixed effects (Geronimus \& Korenman, 1992; Hoffman, Foster, \& Furstenberg Jr., 1993), miscarriage as an instrumental variable (Ermisch \& Pevalin, 2003), or discrete factor models of treatment effect (Kane et al., 2013). A causal link would show that the low socioeconomic status of young mothers is due to opportunity costs rather than selection, whereas absence of such a link would demonstrate the opposite.

Many studies have ignored induced abortions and focused only on the effect of teen birth on later socioeconomic status (Ermisch \& Pevalin, 2003; Geronimus \& Korenman, 1992; Hoffman et al., 1993; Kane et al., 2013; Lee, 2010) or treated everyone who experienced a teen pregnancy the same regardless of the outcome of that pregnancy (Diaz \& Fiel, 2016). Due to severe underreporting of abortion in surveys (Jones \& Kost, 2007), studying those who had an abortion as a separate group has often not been possible (e.g. Diaz \& Fiel, 2016). Such research is needed, however, as it is of interest to describe whether women who avoid becoming teen mothers by obtaining an abortion end up in a different socioeconomic position compared to those who had no teen pregnancy or those who gave birth. The few previous studies including abortion showed terminating a pregnancy before age 20 (Fergusson, Boden, \& Horwood, 2007 in New Zealand) or 25 (Olsson et al., 2014 in Australia) was associated with a higher socioeconomic status later in life than among teen mothers, but lower than among those who had no pregnancy in adolescence (controlling for parents' socioeconomic status).

Women who give birth or obtain abortions as teenagers are likely to share a range of characteristics making them susceptible to teen pregnancy. Thus, studying those who had a teen birth and those who had an abortion separately gives more nuanced information about how teen pregnancy is associated with socioeconomic outcomes than only studying teen mothers, and whether choosing an abortion rather than a birth might be associated with improved socioeconomic outcomes. It is important to keep in mind, though, that selection influences who chooses an abortion. Pregnant teens from less advantaged backgrounds are more likely to choose to give birth than those from higher socioeconomic backgrounds (Ermisch \& Pevalin, 2003 in the UK; Väisänen \& Murphy, 2014 in Finland).

Most studies have ignored that teen pregnancy may be more harmful in socioeconomic terms for those from backgrounds where teen parenthood is atypical. Opportunity costs of teen childbearing may be the highest for women from high socioeconomic backgrounds facing promising career prospects (Diaz \& Fiel, 2016). The aim of this study is to address this gap by using register data of women born between 1975 and 1979 in Finland to examine whether their level of education at age 30 depends on their teenage pregnancy history (no pregnancy, birth, or abortion) and to what extent this relationship interacts with the socioeconomic background of their parents. Finally, I examine whether having a partner at the time of and since the teen pregnancy modifies the association between teen births (or abortions) and education. If partners provide help with childrearing, having one may mitigate the opportunity costs of teen childbearing. I chose level of education as the outcome of interest, because early childbearing may lead to difficulties in attending school due to childrearing responsibilities. Low education is associated with a higher chance of unemployment and low income, thus correlating with socioeconomic position (see e.g. Taylor, 2009 in the US).

Register data can mitigate the shortcomings of survey data, such as underreporting of abortion. Registers provide large sample sizes and do not suffer from attrition, underreporting, or recall bias. 
However, these data do not allow for causal inference, as only a limited amount of information on the background characteristics of these women is available (see Data and methods section). The strength of this study is twofold: 1 ) the large sample size allows for reliable estimation of the interaction between teenage births/abortions with parental socioeconomic background; and 2) I am able to compare the outcomes of those who had a birth to those who had an abortion.

The Finnish context is interesting for a study on this topic. Finland has had one of the lowest teen childbearing rates and the lowest teen abortion rate among Nordic countries since the mid-1980s (Bender, Geirsson, \& Kosunen, 2003; Leppälahti, Gissler, Mentula, \& Heikinheimo, 2012). In the mid1980s the teenage abortion rate in Finland was 20 per 1000 women aged 15 to 19 . It declined to 10 in the mid-1990s but increased to around 14 per 1000 women around the end of the decade (Gissler \& Heino, 2011; Leppälahti et al., 2012; Vuori \& Gissler, 2013). The teenage birth rate declined from 27 per 1000 women in 1975 to 10 in 1999 and 8.5 in 2009 (Gissler \& Heino, 2011). In Finland, abortions can be obtained due to 'social reasons' within the first trimester. If the woman is younger than 17 , or there is another special social reason for abortion, an abortion can be allowed until the end of 20 weeks' gestation (FINLEX, 2013; Knudsen et al., 2003).

The education system, which is free of charge, consists of comprehensive and compulsory basic education at primary and lower-secondary levels (9-10 years), after which one can choose to leave school or to enter vocational or academic uppersecondary education (typically three years), before potentially studying an undergraduate-level degree (or above) in tertiary education (Aho, Pitkanen, \& Sahlberg, 2006). A high proportion of Finns study beyond the compulsory lower-secondary level. For instance, in $2014,73 \%$ of the population aged $25-$ 34 had at least upper-secondary education (Official Statistics of Finland, 2015). Therefore, I focus on the likelihood of obtaining tertiary education as the outcome - there would not be much variation in the outcome if it were 'upper-secondary level or higher'.

\section{Data and methods}

Nationally representative data on women born between 1975 and 1979 were obtained from the Register of Induced Abortions, the Medical Birth Register, and the Population Register of Finland.
Statistics Finland linked these registers using a unique identification number held by each permanent resident in Finland. The register aims to capture all induced abortions performed in Finland. Evaluation studies have found these registers to be reliable, capturing $97 \%$ of abortions (Gissler \& Shelley, 2002; Heino, Niinimäki, Mentula, \& Gissler, 2017).

The data were selected using two-stage sampling. First, an $80 \%$ random sample of those women who had had at least one abortion since age 15 and before year 2010 (the end of the study period) was selected $(\mathrm{N}=20,844)$. All women who had ever had an abortion were not included in the data, because Statistics Finland does not allow the use of complete (sub-)populations for research purposes on ethical grounds. Second, a comparison group, twice the size of the abortion group, of women who had not had an abortion were selected using random sampling $(\mathrm{N}=41,248)$. I use weights to account for this sampling design. Overall the unweighted sample includes almost half of the women born between 1975 and 1979. See Väisänen (2015) for more information about the dataset, which was extracted from a larger study.

The outcome variable is the level of education at age 30: low (lower-secondary level); middle (uppersecondary level); and high (tertiary education).

The variable measuring teen pregnancy includes three mutually exclusive categories: no pregnancy, one abortion, or one birth between ages 15 and 19 . Thus, I excluded women who had more than one teen pregnancy $(\mathrm{N}=1,119,1.8 \% \text { of the sample })^{1}$. Since the associations between teen pregnancy and education probably are stronger among these women, the estimates in this study are conservative. I chose to focus on ages 15-19, since there was no information about pregnancies before age 15 in my dataset and because many previous studies of adolescent pregnancy have focused on women younger than 20 (e.g. Bender et al., 2003; Driscoll, 2014; Lee, 2010; Taylor, 2009; Väisänen \& Murphy, 2014). I conducted robustness checks with teen pregnancy divided into two categories: early teen pregnancy (ages 15-17) and late teen pregnancy (ages 18-19), but the differences between these groups were small.

Parents' socioeconomic status represents the highest occupational status among the adult members of the teen's household, regardless of whether that was held by the woman's mother, 
father, or a step-parent. The choice regarding which status was the highest was made by Statistics Finland. Parents' socioeconomic status was measured when the women were approximately 15 years old. The categories include upper- or lowerlevel non-manual employee; manual worker²; or other. Upper-level employee is regarded as the highest status followed by lower-level employees and manual workers. 'Other' category includes farmers, students, and pensioners, as well as those who are self-employed, long-term unemployed, outside the workforce, and outside the other categories (Official Statistics of Finland, 2013). Thus, most people in this group are relatively disadvantaged, but the group is heterogeneous and therefore difficult to position within the hierarchical order. Place of residence (level of urbanisation and province) at the age of 15 was measured in these data, but other measures of the childhood circumstances of these women were not available.

The relationship status variable has three categories including 'no partner at the time of teen pregnancy (or no teen pregnancy)', 'stable partnership since the teen pregnancy', and 'had partner at the time of the teen pregnancy but the union dissolved'. Partner is defined as a cohabiting or marital partner, as no data on non-cohabiting relationships is available in population registers.

Overall 53,252 women were included in the analyses. I excluded those missing crucial information, such as parents' socioeconomic status, and those who emigrated or died before age 30. I included only those born in Finland and speaking one of the official languages, Finnish or Swedish, as their native language. This was due to detailed information about the country of origin among nonnative Finns being missing from my dataset. Cultural background and immigration status is associated with fertility behaviour and the likelihood of abortion (e.g. Adserà, Ferrer, SigleRushton, \& Wilson, 2012; Malin \& Gissler, 2008; Stonawski, Potancokova, \& Skirbekk, 2016). Not being able to account for this variation would have made the results regarding immigrant women difficult to interpret ${ }^{3}$.

I analysed these data using cross tabulations and logistic regression. I ran two regression models: one for all women and one for those who experienced a teen pregnancy. The first model tests the interaction between teen births/abortions and parental socioeconomic status; the latter the interaction between teen births/abortions and relationship status in addition to parental socioeconomic status. I show the results as odds ratios and average marginal effects at representative values (i.e. predicted probabilities) (see Williams, 2012). All analyses were conducted in Stata 14.

\section{Results}

\section{Descriptive statistics}

Approximately $3.8 \%$ of women had an abortion before age 20 and $2.5 \%$ had a birth (table 1). Out of first pregnancies before age $20,60 \%$ ended in abortion (not shown). Those who obtained an abortion as a teenager more often had tertiary education at age 30 than those who gave birth, but less often than women who did not experience a teen pregnancy. Women from manual worker backgrounds had completed tertiary education less often by age 30 than those from higher socioeconomic backgrounds, particularly those from upper-level employee backgrounds (table 1).

Teen pregnancies were more common among those from manual worker backgrounds $(4.2 \%$ of those from manual worker backgrounds had an abortion, 3.2\% a birth) than among those from upper-level employee backgrounds (2.6\% abortion, $0.6 \%$ birth) (not shown). The other socioeconomic groups were between these two.

\section{Regression results}

The odds of having received at least tertiary education were the highest among those with no teen pregnancy, followed by those who had an abortion. Those from the highest parental socioeconomic background were the most likely to be highly educated. The interaction between these two variables was not statistically significant $(p=0.395$, joint Wald-test, not shown), indicating that teen birth or abortion experiences are not differently associated with the odds of obtaining tertiary education depending on parental socioeconomic background (table 2 , model 1 ). 
Table 1. Weighted \% of explanatory variables by level of education, unweighted $\mathrm{N}$ in each category, and the weighted \% of each explanatory variable category in the total sample.

\begin{tabular}{|c|c|c|c|c|c|c|}
\hline Level of education & $\begin{array}{l}\text { Lower } \\
\text { secondary }\end{array}$ & $\begin{array}{l}\text { Upper } \\
\text { secondary }\end{array}$ & Tertiary & Total & $\begin{array}{l}N \text { (un- } \\
\text { weighted) }\end{array}$ & $\begin{array}{l}\% \text { of } \\
\text { total }^{a}\end{array}$ \\
\hline & 7.8 & 48.6 & 43.6 & 100 & 53,252 & \\
\hline \multicolumn{7}{|l|}{ Teen pregnancy $(p<0.001)$} \\
\hline No teen pregnancy & 6.6 & 47.9 & 45.5 & 100 & 47,039 & 93.6 \\
\hline Abortion & 19.6 & 59.8 & 20.7 & 100 & 4,577 & 3.8 \\
\hline Birth & 35.4 & 57.7 & 7.0 & 100 & 1,636 & 2.5 \\
\hline \multicolumn{7}{|c|}{ Parental socioeconomic status $(p<0.001)$} \\
\hline Manual worker & 8.9 & 55.4 & 35.7 & 100 & 16,816 & 35.0 \\
\hline Other & 7.6 & 50.6 & 41.8 & 100 & 13,286 & 28.2 \\
\hline Lower-level employee & 6.6 & 46.3 & 47.2 & 100 & 9,793 & 20.8 \\
\hline Upper-level employee & 3.8 & 31.0 & 65.2 & 100 & 7,129 & 16.0 \\
\hline \multicolumn{7}{|l|}{ Partnership status $(p<0.001)^{b}$} \\
\hline No partner/pregnancy & 7.4 & 48.3 & 44.3 & 100 & 51,778 & 97.9 \\
\hline Stable partner & 28.5 & 62.1 & 9.4 & 100 & 546 & 0.9 \\
\hline Dissolution from partner since & 30.5 & 60.1 & 9.4 & 100 & 922 & 1.3 \\
\hline \multicolumn{7}{|c|}{ Number of children age $30(p<0.001)$} \\
\hline No children & 6.0 & 43.0 & 51.0 & 100 & 23,851 & 47.1 \\
\hline One child & 7.1 & 46.6 & 46.3 & 100 & 12,445 & 22.7 \\
\hline Two children & 8.7 & 56.8 & 34.5 & 100 & 11,932 & 21.4 \\
\hline Three or more children & 17.6 & 63.9 & 18.5 & 100 & 5,024 & 8.8 \\
\hline \multicolumn{7}{|c|}{ Place of residence at age 15: level of urbanisation $(p<0.001)$} \\
\hline Urban & 8.8 & 47.1 & 44.1 & 100 & 32,730 & 60.8 \\
\hline Semi-Urban & 6.5 & 50.5 & 43.0 & 100 & 10,099 & 19.3 \\
\hline Rural & 5.8 & 51.7 & 42.5 & 100 & 10,322 & 19.9 \\
\hline \multicolumn{7}{|c|}{ Place of residence at age 15: province $(p<0.001)$} \\
\hline South & 9.8 & 48.5 & 41.7 & 100 & 19,410 & 35.9 \\
\hline West & 6.8 & 49.6 & 43.6 & 100 & 19,040 & 36.3 \\
\hline East & 6.4 & 46.5 & 47.1 & 100 & 6,686 & 12.8 \\
\hline Oulu & 6.3 & 48.5 & 45.1 & 100 & 5,515 & 10.6 \\
\hline Lapland & 6.4 & 46.1 & 47.5 & 100 & 2,307 & 4.2 \\
\hline Aland & 13.6 & 73.2 & 13.2 & 100 & 193 & 0.3 \\
\hline
\end{tabular}

Notes: ${ }^{\mathrm{a}}$ Columns total $100 \%$; $^{\mathrm{b}}$ Refers to partnership status at the time of teen pregnancy. 
Table 2. The association between explanatory variables and tertiary education among all women (model 1 ) and those who had a teen pregnancy (model 2), odds ratios (ORs) and standard errors [se].

\begin{tabular}{|c|c|c|c|c|}
\hline \multirow[b]{2}{*}{ Variable } & \multicolumn{2}{|l|}{ Model 1} & \multicolumn{2}{|l|}{ Model 2} \\
\hline & OR & [se] & OR & [se] \\
\hline \multicolumn{5}{|l|}{ Teen pregnancy } \\
\hline No teen pregnancy (ref.) & 1.00 & & $(n / a)$ & \\
\hline Abortion & $0.37 * * *$ & {$[0.03]$} & 1.00 & \\
\hline Birth & $0.18^{* * *}$ & {$[0.04]$} & $0.37^{* * *}$ & {$[0.10]$} \\
\hline \multicolumn{5}{|l|}{ Parental socioeconomic status } \\
\hline Manual worker (ref.) & 1.00 & & 1.00 & \\
\hline Other & $1.24 * * *$ & {$[0.03]$} & $1.29 *$ & {$[0.13]$} \\
\hline Lower-level employee & $1.57^{* * *}$ & {$[0.05]$} & $1.41^{* *}$ & {$[0.15]$} \\
\hline Upper-level employee & $3.23 * * *$ & {$[0.11]$} & $2.59 * * *$ & {$[0.33]$} \\
\hline \multicolumn{5}{|c|}{ Interaction: parental socioeconomic status and teen pregnancy } \\
\hline Abortion $\times$ Other & 1.08 & {$[0.11]$} & $(n / a)$ & \\
\hline Abortion x Lower & 0.92 & {$[0.10]$} & $(n / a)$ & \\
\hline Abortion x Upper & 0.83 & {$[0.11]$} & $(n / a)$ & \\
\hline Birth $x$ Other & 0.78 & {$[0.24]$} & 0.73 & {$[0.23]$} \\
\hline Birth $x$ Lower & 1.16 & [0.38] & 1.34 & {$[0.45]$} \\
\hline Birth $\times$ Upper & 0.78 & {$[0.37]$} & 1.00 & {$[0.48]$} \\
\hline \multicolumn{5}{|l|}{ Partnership status ${ }^{a}$} \\
\hline No partner or no teen pregnancy (ref.) & 1.00 & & 1.00 & \\
\hline Stable partner since teen pregnancy & 1.17 & {$[0.22]$} & 1.12 & {$[0.25]$} \\
\hline Dissolution from teen pregnancy partner & 0.88 & {$[0.12]$} & $0.61 * *$ & [0.099] \\
\hline \multicolumn{5}{|l|}{ Interaction: partnership status and teen pregnancy } \\
\hline Birth $\mathrm{x}$ Stable partner since teen pregnancy & $(n / a)$ & & 1.28 & {$[0.50]$} \\
\hline Birth $x$ Dissolution from teen pregnancy partner & $(n / a)$ & & $2.30^{*}$ & {$[0.78]$} \\
\hline \multicolumn{5}{|l|}{ Number of children age 30} \\
\hline No children (ref.) & 1.00 & & 1.00 & \\
\hline One child & $0.90 * * *$ & [0.023] & $0.62 * * *$ & [0.062] \\
\hline Two children & $0.57^{* * *}$ & [0.016] & $0.45^{* * *}$ & [0.046] \\
\hline Three or more children & $0.27^{* * *}$ & [0.013] & $0.26 * * *$ & [0.042] \\
\hline \multicolumn{5}{|l|}{ Place of residence at age 15: level of urbanisation } \\
\hline Urban (ref.) & 1.00 & & 1.00 & \\
\hline Semi-Urban & 1.05 & [0.030] & 1.04 & {$[0.11]$} \\
\hline Rural & 1.04 & {$[0.030]$} & 1.09 & {$[0.12]$} \\
\hline \multicolumn{5}{|l|}{ Place of residence at age 15: province } \\
\hline South (ref.) & 1.00 & & 1.00 & \\
\hline West & $1.23 * * *$ & [0.032] & 1.21 & {$[0.12]$} \\
\hline East & $1.51 * * *$ & [0.053] & $1.80 * * *$ & {$[0.24]$} \\
\hline Oulu & $1.44^{* * *}$ & [0.055] & $1.61 * * *$ & {$[0.23]$} \\
\hline Lapland & $1.55^{* * *}$ & [0.085] & $1.78^{* *}$ & {$[0.33]$} \\
\hline Aland & $0.24 * * *$ & [0.064] & 0.73 & {$[0.41]$} \\
\hline
\end{tabular}


I calculated predicted probabilities of the interaction effect, although it was not statistically significant (figure 1). The results indicate there may be some differences in the association between teen birth/abortion and education depending on parental socioeconomic background, even though statistical significance was not reached. For instance, those from manual worker backgrounds who had a teen birth (abortion) had around 27\%points (19\%-points) lower probability of having tertiary education than those from the same background who had no teen pregnancy. Those from upper-level employee backgrounds who had a birth (abortion) had 43\%-points (27\%-points) lower probability of having obtained tertiary education than those from the same background who had no teen pregnancy. As only a small proportion of women became pregnant before age 20 , the confidence intervals are wide and the interaction not statistically significant.

Figure 1. Average marginal effects at representative values of the interaction between parental socioeconomic status and teen births and abortions among all women.

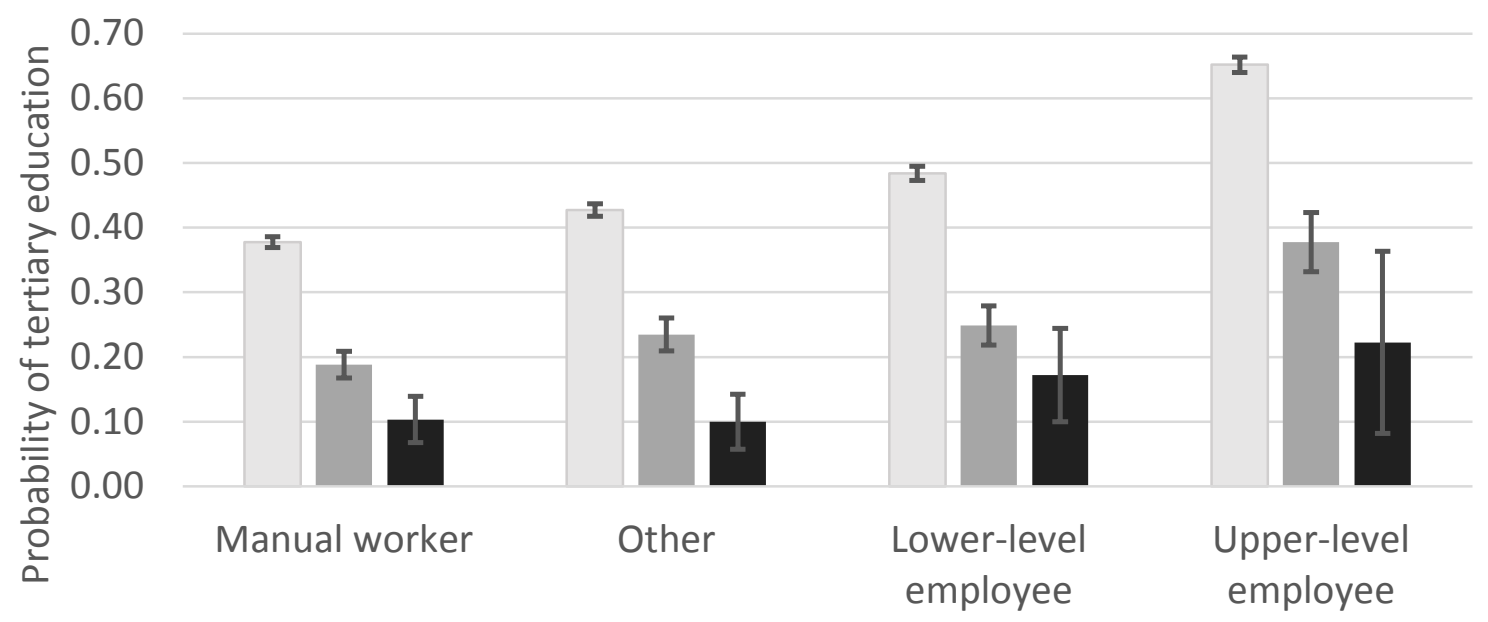

Parental socioeconomic status

No pregnancy Abortion Birth

Notes: Controlling for partnership status, number of children at age 30 , and place of residence; based on model 1 in table 2 . 
The results including only women who experienced a teen pregnancy were similar to model 1 , where all women were included (table 2, model 2). However, while partnership status was not significantly associated with the outcome in model 1, among women who had a teen pregnancy it was. There was also an interaction effect between teen pregnancy outcomes and the partnership status ( $p=0.046$, joint Wald-test of the interaction, not shown). Interestingly, there was almost no advantage in having a partner among those who became teen mothers in terms of education: teen mothers had between $8 \%$ and $11 \%$ probability of having tertiary education. Among those who had an abortion, having separated from their partner since the pregnancy was associated with a probability similar to teen mothers to having tertiary education (13\%), while those who had no partner or had a stable partner, had around $20 \%$ probability (figure 2).

Figure 2. Average marginal effects at representative values of the interaction between partnership status at the time of teen pregnancy and teen births and abortions among women who experienced a teen pregnancy.

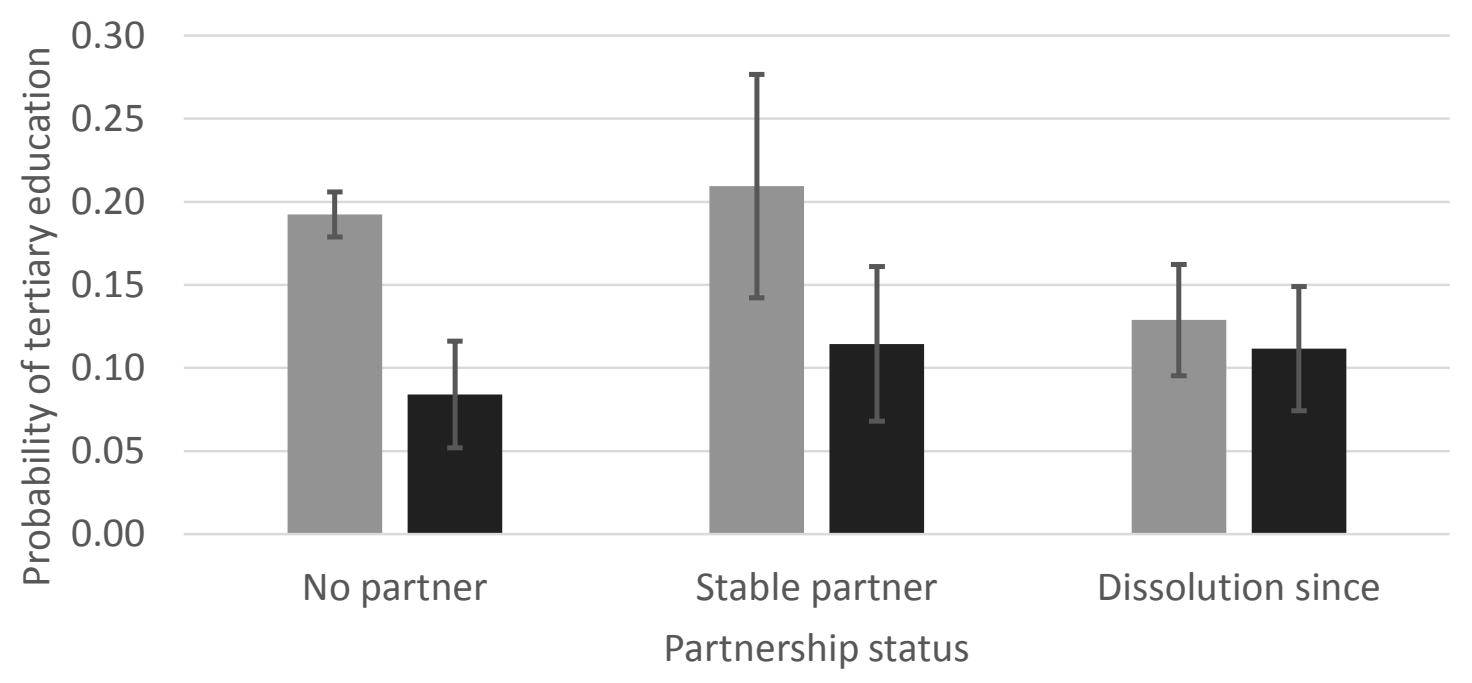

abortion Birth

Notes: Controlling for parental socioeconomic status, number of children at age 30 , and place of residence; based on model 2 in table 2. 


\section{Discussion}

This study examined whether the likelihood of obtaining higher education is differently associated with teen births and abortions depending on socioeconomic background. In line with Diaz and Fiel (2016), there was some indication that those from higher socioeconomic backgrounds may suffer a higher 'penalty' of teen birth than those from lower socioeconomic backgrounds, where teen pregnancies are more common. The gap in the probability of having tertiary education between those with and without a teen birth was the biggest among women from the highest socioeconomic background. However, the interaction was not statistically significant. The lack of statistical significance may have partly been due to the small numbers of women in each teen pregnancy category when stratified by parental socioeconomic status despite the large sample size of over 50,000 women.

A new finding in this study was that the 'penalty' associated with teen abortions was lower than that associated with teen childbearing, but it may vary by parental socioeconomic status. Selection into who has an abortion matters. Some teens may have chosen to terminate their pregnancy in order to finish their education and get stable employment before childbearing (see e.g. Ekstrand, Tydén, Darj, \& Larsson, 2009 in Sweden), but even in the absence of opportunity costs, teens from higher socioeconomic backgrounds who had an abortion may be further behind those from similar backgrounds and no pregnancy than teens from lower socioeconomic backgrounds.

Interestingly, teen mothers did not seem to benefit in socioeconomic terms from having a partner, as it made almost no difference to their likelihood of obtaining tertiary education. Perhaps they never planned to obtain higher education and therefore having a partner sharing childcare responsibilities was not associated with educational achievement. Future studies should investigate the aspirations of young mothers in Finland.

Surprisingly, partnership mattered the most among those who had a teen abortion. Women who separated from their partner after the abortion had a much lower likelihood of obtaining tertiary education than other women who chose abortion the likelihood was close to that of an average teen mother. These women may be a highly selected group, perhaps leading an unstable life overall, which may correlate with a low propensity of obtaining higher education. More studies on the topic are needed.

A limitation in this study was that these women were born in the late 1970s. They were teenagers in the early 1990s and in their thirties ten years ago. Future studies should collect more recent data to examine whether these trends have changed. Teen birth and abortion rates continued to decline in Finland since the early 2000s, reaching $6.3 / 1000$ for births and 8.4/1000 for abortions in 2015 (Heino \& Gissler, 2016; Vuori \& Gissler, 2016). Thus, selection into experiencing teen pregnancy may have become stronger, but at the same time, fewer women experience an early pregnancy, making the population-level effect smaller.

Finland is an interesting case study due to its progressive social security system aimed at reducing opportunity costs of childbearing by ensuring everyone has access to affordable day care and free education (Aho et al., 2006; Haataja, 2006; Vikat, 2004), and due to its relatively low teen pregnancy rates (Bender et al., 2003; Leppälahti et al., 2012). In countries such as the United States or the United Kingdom, where the opportunity costs of childbearing are higher, the differences may be larger. On the other hand, in both of these countries teen pregnancy rates are higher than in Finland, which indicates less strong selection. This may counterbalance any differences between countries like Finland and countries like the US and the UK.

The strengths of this study include the large sample size, no underreporting of abortion, and no attrition. However, the main limitation is that information on the background characteristics was limited, which did not allow me to control for selection into teen pregnancy. Thus, this study cannot formally test whether the lower socioeconomic position of teen mothers is due to selection or opportunity costs (or both). Since teens who chose an abortion and thus avoided opportunity costs had lower education than those with no teen pregnancy, selection seems to play a role, but more information on the background, aspirations, and future plans of these women is needed to confirm this. Nordic countries could be at the forefront of this research by linking population registers to survey data, thus overcoming the main limitations of each data source on its own. 


\section{Acknowledgements}

Many thanks to Professor Mike Murphy, Dr Tiziana Leone and Dr Brienna Perelli-Harris for their comments on earlier versions of the manuscript, and Professor Mika Gissler and Dr Markus Jokela for their expertise help in obtaining the data set. At the time of writing the paper, the author was supported by the Economic and Social Research Council Doctoral Training Centre scholarship [grant number ES/J00070/1]. The author is grateful to Statistics Finland and the National Institute of Health and Welfare for their permissions (TK53162-11 and THL/173/5.05.00/2011 respectively) to use these data.

\section{References}

Adserà, A., Ferrer, A. M., Sigle-Rushton, W., \& Wilson, B. (2012). Fertility Patterns of Child Migrants: Age at Migration and Ancestry in Comparative Perspective. The ANNALS of the American Academy of Political and Social Science, 643(1), 160-189. https://doi.org/10.1177/0002716212444706

Aho, E., Pitkanen, K., \& Sahlberg, P. (2006). Policy Development and Reform Principles of Basic and Secondary Education in Finland Since 1968. Education Working Paper Series, Number 2, 1-166.

Assini-Meytin, L. C., \& Green, K. M. (2015). Long-Term Consequences of Adolescent Parenthood Among African-American Urban Youth: A Propensity Score Matching Approach. Journal of Adolescent Health, 56(5), 529-535. https://doi.org/10.1016/j.jadohealth.2015.01.005

Becker, G. S. (1991). A treatise on the family (Enlarged ed). Cambridge, Mass, London: Harvard University Press.

Bender, S., Geirsson, R. T., \& Kosunen, E. (2003). Trends in teenage fertility, abortion, and pregnancy rates in Iceland compared with other Nordic countries, 1976-99. Acta Obstetricia et Gynecologica Scandinavica, 82(1), 38-47. https://doi.org/10.1034/j.1600-0412.2003.820107.x

Diaz, C. J., \& Fiel, J. E. (2016). The Effect(s) of Teen Pregnancy: Reconciling Theory, Methods, and Findings. Demography, 53(1), 85-116. https://doi.org/10.1007/s13524-015-0446-6

Driscoll, A. (2014). Adult outcomes of teen mothers across birth cohorts. Demographic Research, 30, 12771292. https://doi.org/10.4054/DemRes.2014.30.44

Ekstrand, M., Tydén, T., Darj, E., \& Larsson, M. (2009). An Illusion of Power: Qualitative Perspectives On Abortion Decision-Making Among Teenage Women In Sweden. Perspectives on Sexual and Reproductive Health, 41(3), 173-180. https://doi.org/10.1363/4117309

Ermisch, J., \& Pevalin, D. J. (2003). Does a 'teen-birth' have longer-term impacts on the mother? Evidence from the 1970 British Cohort Study. ISER Working Paper Series, Colchester: Institute of Social and Economic Research, University of Essex, 2003-28.

Fergusson, D. M., Boden, J. M., \& Horwood, L. J. (2007). Abortion among young women and subsequent life outcomes. Perspectives on Sexual and Reproductive Health, 39(1), 6-12.

https://doi.org/10.1363/3900607

FINLEX. (2013). Laki raskauden keskeyttämisestä [Act on pregnancy termination] 24.3.1970/239. Retrieved 4 March 2013, from http://www.finlex.fi/fi/laki/ajantasa/1970/19700239

Geronimus, A. T., \& Korenman, S. (1992). The Socioeconomic Consequences of Teen Childbearing Reconsidered. The Quarterly Journal of Economics, 107(4), 1187-1214. https://doi.org/10.2307/2118385

Gissler, M., \& Heino, A. (2011). Induced abortions in the Nordic countries 2009. Helsinki: National Institute for Health and Welfare.

Gissler, M., \& Shelley, J. (2002). Quality of data on subsequent events in a routine Medical Birth Register. Medical Informatics and the Internet in Medicine, 27(1), 33-38. https://doi.org/10.1080/14639230110119234

Gissler, M., Ulander, V.-M., Hemminki, E., \& Rasimus, A. (1996). Declining Induced Abortion Rate in Finland: Data Quality of the Finnish Abortion Register. International Journal of Epidemiology, 25(2), 376-380. https://doi.org/10.1093/ije/25.2.376 
Haataja, A. (2006). Nordic breadwinner-caretaker models - comparison of Finland and Sweden (Reports of the Ministry of Social Affairs and Health, Finland No. 43). Helsinki: the Ministry of Social Affairs and Health.

Heino, A., \& Gissler, M. (2016). Induced abortions 2015 (Official Statistics of Finland No. 17). Helsinki: National Institute for Health and Welfare.

Heino, A., Niinimäki, M., Mentula, M. J., \& Gissler, M. (2017). How reliable are health registers? Registration of induced abortions and sterilizations in Finland. Informatics for Health and Social Care, 1-10. https://doi.org/10.1080/17538157.2017.1297306

Hoffman, S. D. (1998). Teenage Childbearing Is Not So Bad After All...Or Is It? A Review of the New Literature. Family Planning Perspectives, 30(5), 236. https://doi.org/10.2307/2991610

Hoffman, S. D., Foster, E. M., \& Furstenberg Jr., F. F. (1993). Reevaluating the Costs of Teenage Childbearing. Demography, 30(1), 1-13. https://doi.org/10.2307/2061859

Jones, R. K., \& Kost, K. (2007). Underreporting of Induced and Spontaneous Abortion in the United States: An Analysis of the 2002 National Survey of Family Growth. Studies in Family Planning, 38(3), 187-197. https://doi.org/10.1111/j.1728-4465.2007.00130.x

Kane, J. B., Morgan, S. P., Harris, K. M., \& Guilkey, D. K. (2013). The Educational Consequences of Teen Childbearing. Demography, 50(6), 2129-2150. https://doi.org/10.1007/s13524-013-0238-9

Knudsen, L. B., Gissler, M., Bender, S. S., Hedberg, C., Ollendorff, U., Sundström, K., ... Vilhjalmsdottir, S. (2003). Induced abortion in the Nordic countries: special emphasis on young women. Acta Obstetricia et Gynecologica Scandinavica, 82(3), 257-268.

https://doi.org/10.1034/j.1600-0412.2003.00006.x

Lawlor, D. A., \& Shaw, M. (2002). Too much too young? Teenage pregnancy is not a public health problem. International Journal of Epidemiology, 31(3), 552-553. https://doi.org/10.1093/ije/31.3.552

Lee, D. (2010). The early socioeconomic effects of teenage childbearing: A propensity score matching approach. Demographic Research, 23, 697-736. https://doi.org/10.4054/DemRes.2010.23.25

Leppälahti, S., Gissler, M., Mentula, M., \& Heikinheimo, O. (2012). Trends in teenage termination of pregnancy and its risk factors: a population-based study in Finland, 1987-2009. Human Reproduction, 27(9), 2829-2836. https://doi.org/10.1093/humrep/des253

Malin, M., \& Gissler, M. (2008). Induced abortions among immigrant women in Finland. Finnish Journal of Ethnicity and Migration, 3(1), 2-12.

Mollborn, S. (2010). Exploring Variation in Teenage Mothers' and Fathers' Educational Attainment. Perspectives on Sexual and Reproductive Health, 42(3), 152-159. https://doi.org/10.1363/4215210

Official Statistics of Finland. (2013). Classification of Socio-economic Groups 1989. Retrieved 2 December 2013.

Official Statistics of Finland. (2015). Educational structure of population 2014. Retrieved 14 December 2015.

Olausson, P. O., Haglund, B., Weitoft, G. R., \& Cnattingius, S. (2001). Teenage Childbearing and Long-Term Socioeconomic Consequences: A Case Study in Sweden. Family Planning Perspectives, 33(2), 70-74. https://doi.org/10.2307/2673752

Olsson, C. A., Horwill, E., Moore, E., Eisenberg, M. E., Venn, A., O'Loughlin, C., \& Patton, G. C. (2014). Social and emotional adjustment following early pregnancy in young Australian women: A comparison of those who terminate, miscarry, or complete pregnancy. Journal of Adolescent Health, 54(6), 698703. https://doi.org/10.1016/i.jadohealth.2013.10.203

Paranjothy, S., Broughton, H., Adappa, R., \& Fone, D. (2009). Teenage pregnancy: who suffers? Archives of Disease in Childhood, 94(3), 239-245. https://doi.org/10.1136/adc.2007.115915

Smith, D. M., \& Roberts, R. (2011). Social inequality and young pregnancy: the causal attributions of young parents in London, UK. Health \& Place, 17(5), 1054-1060.

https://doi.org/10.1016/j.healthplace.2011.06.009

Stonawski, M., Potancokova, M., \& Skirbekk, V. (2016). Fertility Patterns of Native and Migrant Muslims in Europe. Population Space and Place, 22(6), 552-567. https://doi.org/10.1002/psp.1941

Taylor, J. L. (2009). Midlife Impacts of Adolescent Parenthood. Journal of Family Issues, 30(4), 484-510. https://doi.org/10.1177/0192513X08329601 
Väisänen, H. (2015). The association between education and induced abortion for three cohorts of adults in Finland. Population Studies, 69(3), 373-388. https://doi.org/10.1080/00324728.2015.1083608

Väisänen, H., \& Murphy, M. (2014). Social Inequalities in Teenage Fertility Outcomes: Childbearing and Abortion Trends of Three Birth Cohorts In Finland. Perspectives on Sexual and Reproductive Health, 46(2), 109-116. https://doi.org/10.1363/46e1314

Vikat, A. (2004). Women's Labor Force Attachment and Childbearing in Finland. Demographic Research, Special 3, 177-212. https://doi.org/10.4054/DemRes.2004.S3.8

Vuori, A., \& Gissler, M. (2013). Perinatal statistics: parturients, deliveries and newborns 2012 (Official Statistics of Finland). Helsinki: National Institute for Health and Welfare.

Vuori, E., \& Gissler, M. (2016). Perinatal statistics: parturients, deliveries and newborns 2015 (Official Statistics of Finland No. 16). Helsinki: National Institute for Health and Welfare.

Williams, R. (2012). Using the margins command to estimate and interpret adjusted predictions and marginal effects. The Stata Journal, 12(2), 308-331.

\section{Endnotes}

1. The 'no pregnancy group' includes those who had miscarriages and/or stillbirths, as no information of these pregnancy outcomes was included in my dataset. Sensitivity analyses including women who had more than one teen pregnancy were conducted and the interpretation of the main results remained qualitatively the same.

2. Upper-level employees are in managerial, professional, and related occupations, whereas lower-level employees have administrative and clerical occupations. Manual workers typically work in manufacturing or distribution of goods and services. (Official Statistics of Finland, 2013).

3. Sensitivity analyses including migrant women were conducted. The results regarding the effect of parental socioeconomic status and teen pregnancy on education remained largely unchanged. Those from migrant origins were less likely to obtain higher education than those from a Finnish background. 